\title{
Opportunities to increase innovation activity in small and medium-sized industrial enterprises
}

\author{
Siyka Demirova ${ }^{1}$, Sibel Ahmedova ${ }^{1}$ \\ 1.Technical University of Varna, dep. Industrial Management, Studentska Str. 1,Varna 9010, Bulgaria \\ Corresponding author contact: s demirovaltu-varna.bg
}

\begin{abstract}
In the context of increased market competition, SMEs continue to face market and consumption-induced problems related to the acquisition and maintenance of competitive advantages. In this regard, an important factor for the efficiency and improved economic performance of SMES is the implementation of innovation and the introduction of an active innovation policy. The purpose of the present article is, based on a research analysis, to set out the guidelines for enhancing the innovation activities in the small and medium-sized industrial enterprises.
\end{abstract}

Keywords: innovation activity, competitive advantages, innovation policy

\section{$1 \quad$ Introduction}

Small and medium-sized industrial enterprises (hereafter SMEs) are referred to as the "backbone" of the European and Bulgarian economy. They are a major source of growth and job creation. At the same time SMEs are reported as being the most sensitive economic entities to the changes of the business environment.

Improving innovation management, reforming social services and paying greater attention to human resources is one of the priorities for future development. On the one hand, this necessitates a reorientation of the enterprise activities from globally widespread, low value-added manufacturing to certain niches, established based on specific competitive advantages and innovative products with higher benefit. On the other hand, it is related to adopting long-term business flexibility and active innovation policy based on new technologies and innovation development in line with the rapidly changing market conditions and under careful investigation in search of new market niches and partners.

\section{Importance of innovation for the economic activity of the small and medium-sized industrial enterprises}

Since the beginning of the last century researchers have been intensely interested in issues related to innovations, their nature, role, content and specificity of their conceptual apparatus. Under the current conditions of a dynamic and highly competitive environment, these issues continue to be relevant and almost tangible in today's scientific and research activities.

Over the last few years, there has been a growing interest in issues exploring the relationship between innovation and competitiveness. This interest is not accidental and is because enhancing enterprise competitiveness is of decisive importance to the national economy and social prosperity. However, changes in consumer needs and requirements, the highly dynamic environment and the rapid ageing of current techniques and technology will make the enterprises' competitive positions unreliable and insecure. New requirements emerge for their proper functioning, and they are driven by the need for rapid continuous changes and improvement. Innovations become a key factor for success. Constant revision of the issues related to innovation and competitiveness ensure their continuing relevance. 
Various studies into the subject under discussion provide conclusive evidence as to the relationship between the enterprise innovation and competitiveness. The main assertion is that enterprise innovation drives their competitiveness (Ren, Zhang, Yi, 2010). This relationship is to be sought mainly in two directions. On the one hand, it is proven by the inclusion of innovativeness and innovation as an indicator used in the different methods and tools for measuring and assessing enterprise competitiveness. On the other hand, there are some studies, binding the methods for assessing the enterprise innovativeness with that measuring enterprise competitiveness and seeking for the interrelationship existing between them. However, experts differ in their opinion as to the above-mentioned issue.

This may be the reason why innovation is considered a process that involves the interaction of many different factors. Successful application of innovations (product and process) depends not only on the technological capabilities but also on other key factors in the field of manufacturing, marketing, organization, strategic planning, training and resource allocation. Therefore, company-level innovation is seen as a complex category of multifaceted nature that is influenced by a variety of factors and cannot be measured with a single indicator (Minarelli, Raggi, Viaggi, 2014). Technological innovation can be seen as a special asset of the enterprise that includes various key areas such as technology, production, process, knowledge, experience, organization, and others. All in all, the success of a given innovation requires a wide variety of assets, resources and opportunities. Therefore, technological innovation must be measured in terms of different activities and levels, it must also be consistent with the overall strategy of the company, should be compatible with certain specific environmental conditions and peculiarities in order for the firm to obtain a competitive advantage which in turn will affect the company performance.

Lawless and Fisher (1990) identify the relationship between innovation and competitiveness by claiming that the successful introduction of new products can provide firms with the potential to improve their market position and make more sustained returns than would otherwise have been possible.

Evangelista (2000) regards R \& D activities as a central component of those activities that are related to the firms' technological innovations and as the most important intangible costs of innovation. According to Peteraf (2016) the firm's heterogeneous portfolio of resources (including human resources, capital, technology resources, etc.) and their constant renewal are the primary cause for improving the financial returns, and which the author regards as a factor for enhancing competitiveness.

Adler and Shenbar (Velev, 2004) also argue that technological innovation of enterprises influences their competitiveness. They believe technological innovation consists of four elements:

- capacity to develop new products that meet market needs;

- capacity to implement appropriate technologies and processes for the production of new products;

- capacity to develop and adopt new products, processes and technologies to meet future needs and

- capacity to respond to incidental technological activities and unexpected opportunities created by competitors.

The existence of a interrelationship between innovation and competitiveness is also confirmed in the study "Competitiveness of Bulgarian Industrial Companies " (Iliev Y., 2005). The authors believe that the innovations introduced in the industrial companies affect the competitiveness in two directions - the characteristic features of the sector and the competitive position of the company.

Advanced in the study is the statement that the influence of innovation on the industry characteristics is primarily considered the impact made upon the five forces influencing the intensity of the competitive struggle and the ability of the company to choose a favorable position for itself as compared to them. The authors believe that innovations can improve the company's ability to choose a position favorable to it itself as compared to the five competitive forces and at the same time that innovations in competitive firms may worsen the company's position in this respect. Concurrently, innovations can exert a favourable or adverse effect upon the company's competitive position individually as relative to each of the five competitive forces. In addition, briefly outlined in the study are the ways in which innovations might affect the company's competitive position:

- Reducing current product costs-i.e.reducing the production costs for manufacturing of currently existing products. 
- Improving the technical and operational characteristics of the manufactured products.

- A combination of reducing current product costs and improving the technical and operational characteristics of the manufactured products

- Introducing new products in the process of manufacturing.

In this regard, the authors of the above-mentioned study add that the opportunities innovation provides to reduce production costs can be used by market leaders to strengthen their own positions. Furthermore, innovations can be used by emerging competitors who have the potential to overcome their initial unfavorable position in terms of expenditures incurred and gain a more favorable for them position. They also indicate that the company can choose a differentiation strategy that aims to improve the technical and operational performance of its products through innovation. Differentiation based on such a strategy can only be successful if the market or its specific segment perceives the product's specific characteristics as advantages and appreciates them to such an extent that it is willing to pay an additional premium above the average market price. Consumer assessment is, therefore, the one that determines the market size and the price level at which the product will be attractive. According to the study, the analysis of the interconnection between innovation and competitiveness can be oriented in two directions - analysis of the external business environment (European and national dimensions) and the internal business environment.

The main directions, developing good economic activity, effective management, and successful realization of approved planned profit are characterized by innovative activities such as:

- continuous marketing research related to the study of existing markets, innovative development of competitive enterprises, studies of social measurements, human resources development, etc.;

- sustained research and analysis of the opportunities for production and deployment of new innovative products. It would be constructive and effective if, within reach, the enterprise performs this activity only or uses the services of innovation centers, universities, branch institutes, etc;

- supply - due to the global shortage of resources, this issue must become the central focus of attention of the enterprise activities. It is best to make good use of local resources. In the absence of such resources, the global market should be critically examined to exploit new (alternative) sources for resources. In this regard, the procurement organization plays an important role by contributing to the success of the enterprise;

- technology and organization of production - new technologies and well-organized enterprise activities are the basis for its success. To this effect, new technologies and new forms of organization and management should always be adopted to respond to external innovation development activities. This means that the external factors affecting the enterprise and creating a particular electronic and other environment should be incorporated within the existing forms of organization and management established in the enterprise. In essence, the enterprise should create the necessary opportunities for rapid adaptation and response to the electronic requirements of external institutions;

- sales - they should be organized in such a way as to shorten the "production - user" cycle and reduce the relative share of costs and their accomplishment;

- personnel- the staff should be highly qualified, allowing for combinability or interchangeability of their professional competences with a balancing criteria between employee's age (related restrictions) and accumulated experience;

- finance - the enterprise should strive for good financial standing. 


\section{Distinctive features of the innovation activity of small and medium-sized industrial enterprises in Bulgaria}

Barriers to the development and dissemination of innovation in Bulgaria are, unfortunately, great in number and in variety. The most limiting (hampering) factor is the lack of suitable sources of business funding. An additional reason, no less important, is the large share of low- income population with unpretentious commercial demands. The lesser or weak innovation activity of SMEs in Bulgaria is also due to the lack of a National Innovation System allowing for at least some of the active SMEs to transfer and implement innovations (Entrepreneurship Survey and Prospects for Development of Innovation in SMEs (2012-2013)).

According to NSI data for $2016,73 \%$ of R \& D expenditures is for private sector enterprises. In the public sector, their relative share is $21 \%$. The most insignificant share is for the R \& D expenditures in higher (tertiary) education (5\%) and non-profit organizations (1\%) (NSI, 2017).

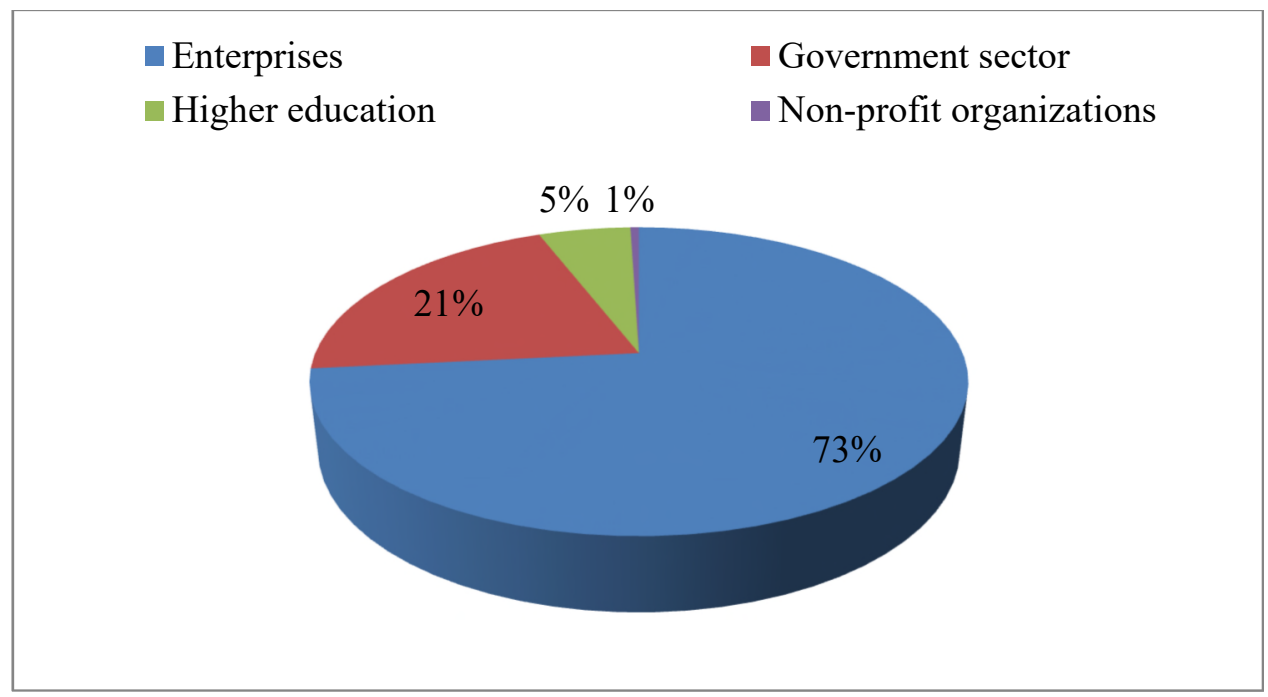

Fig. 1. Structure of R \& D expenditures by institutional sector in 2016

The SMEs innovation activities covering the period 2014 - 2016 is higher in the industrial enterprises $(29.7 \%)$ than those engaged in the provision of services $(21.9 \%)$. The largest share is that of the innovators in the group of large enterprises (250 and more employees) - 78.3\%. The turnover of innovative enterprises accounts for $57.8 \%$ of the turnover of all the enterprises. The total share of the employees in the innovative enterprises is $53.8 \%$ of the employees in all enterprises (Table 3. 1) (National statistical institute,2017).

Table 1. Innovation activity during the period 2014 - 2016 by economic sectors and size of enterprises.

\begin{tabular}{|c|c|c|c|}
\hline & $\begin{array}{c}\text { Innovative } \\
\text { enterprises } \\
\%\end{array}$ & $\begin{array}{c}\text { Turnover of } \\
\text { innovative enterprises } \\
\%\end{array}$ & $\begin{array}{c}\text { Employees in } \\
\text { innovative enterprises } \\
\%\end{array}$ \\
\hline Total & 26,1 & 57,8 & 53,8 \\
\hline Industry & 29,7 & 75,2 & 57 \\
\hline Services & 21,9 & 41,2 & 48,7 \\
\hline 10 - 49 employees & 20,6 & 21,5 & 22,8 \\
\hline $50-249$ employees & 38,8 & 45,3 & 42,4 \\
\hline 250 and more employees & 78,3 & 88,8 & 80,4 \\
\hline
\end{tabular}

During the period 2014-2016 innovation activity decreases by 1.3 percentage points compared to the previous survey. Growth is observed only with the product innovations ( 0.1 points), while decrease 
is registered in marketing, organizational and process innovations - by 2.5, 1.6 and 0.1 points, respectively (Figure 3.2 ) (National statistical institute, Statistical reference book, 2017).

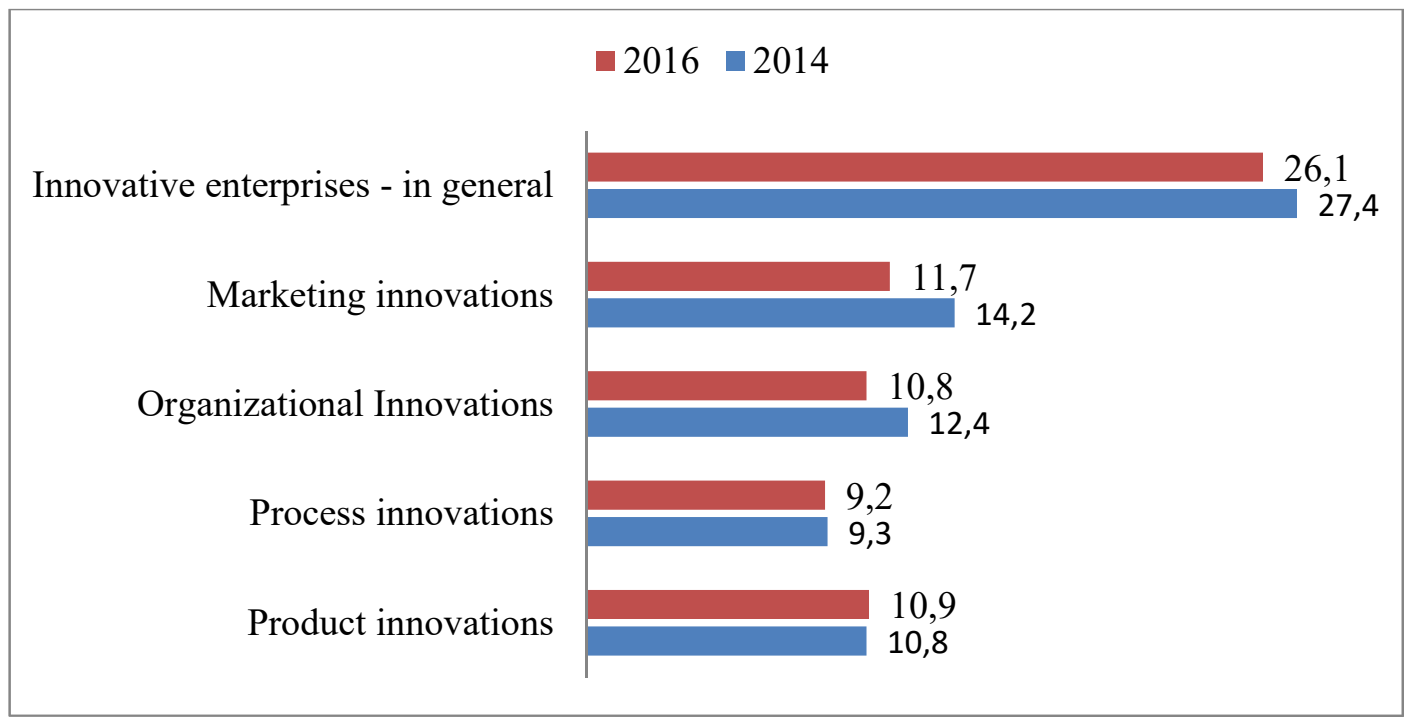

Fig. 2. Relative share of enterprises with innovative activity

During the period 2014-2016, 10.9\% of the enterprises have launched new or significantly improved goods or services (product innovations) and their turnover is $22.8 \%$ of the 2016 total turnover rates. $52.4 \%$ of the product innovation companies have introduced an innovative product that is new to their market and $79.3 \%$ have offered goods or services that are only new as to their own enterprise. $4.8 \%$ of the 2016 turnover in the industry and services sectors is due to new products as to either the enterprise itself or the market as a whole. $2.2 \%$ of the enterprise turnover in 2016 is the result of new product innovations not only as to the enterprise itself, but also as to the market as a whole, while $2.6 \%$ of the turnover results from new products only as to the enterprise itself. During the period under survey $9.2 \%$ of the enterprises have implemented new or significantly improved processes (process innovations) in their enterprise. 5.9\% have introduced new or significantly improved production methods, $4.7 \%$ of the enterprises have implemented new or significantly improved auxiliary activities and $2.3 \%$ - new or significantly improved methods of procurement, supply and distribution of raw materials, goods and services. $10.8 \%$ of the enterprises apply new organizational methods in the enterprise's business practices, workplace organization and external relationships with other enterprises and organizations that have not previously been used in that enterprise (organizational innovations). The most frequently mentioned types of organizational innovations are the introduction of new methods of work organization related to the allocation of responsibilities and decision-making $(7.5 \%)$ and the implementation of new business practices for organizing the working process (7.2\%). During the reporting period, $11.7 \%$ of the enterprises have introduced new marketing concepts and strategies (marketing innovations). The largest share is that of the enterprises (7.3\%) applying new advertising methods or product promotion techniques followed by those enterprises using new methods for pricing of their goods and services $(6.2 \%)$.

\section{Guidelines for increasing SMEs innovative activities}

The ongoing processes occurring in both national and international spheres of operation and the membership of Bulgaria in the EU inevitably lead to a significant increase in the level of competition and bring about considerable changes in its very nature. For the successful entry into the European single market, the innovation potential of the enterprises should be improved in two directions (aspects): on the one hand, to improve the enterprises' innovation processes and, on the other, to create prerequisites for the private sector to absorb fully the achievements of science. This requires raising the level of knowledge and experience within enterprises themselves and creating effective mecha- 
nisms for the transfer of know-how as well. Accordingly, presented below are some guidelines for enhancing SMEs innovative activities such as:

- Enhancing the industrial enterprises' culture of entrepreneurship and innovation.

- Investing in human capital and intensive exchange of technological and production experience.

- Expanding the technical and technological level of the process of manufacturing, promoting widespread use of information technologies not only in all subsystems of the enterprise but also in their relationships with external economic agents and institutions.

- Taking full advantage of the enterprise opportunities for technological transfer and cooperation

- Setting up public-private partnerships, interacting closely with the research sectors and centers for entrepreneurship already established in the system of higher education,

- Promoting collaboration in the development and implementation of innovative projects: developing joint projects through targeted programs; assigning priority to projects leading to innovative development; fostering joint innovative projects at a regional level supported by regional agencies and the respective municipalities; encouraging participation in regional networks or processes.

- Facilitating innovation activities in the enterprises, incl. the development and introduction of new products, processes and enterprise business modelling.

- Extending the current scope of the employed financial instruments and increasing the share of spending on innovative projects (especially on R \& D).

\section{Conclusion}

1. Explored in the article is the relationship between industrial enterprise innovativeness and competitiveness in two main directions:

- inclusion of innovativeness and innovation as an indicator in various methods and instruments for measuring and evaluating the company's competitiveness;

- research into the opportunities of binding the methods for assessing the enterprise innovative activities with those measuring the enterprise competitiveness and seeking the interconnectedness between them.

2. Outlined on the basis of the empirical analysis are some practical guidelines for improved innovative activities in small and medium-sized industrial enterprises.

- Analyzed are the reasons why business innovation activities are important to the small and medium industrial enterprises ;

- Systematized are the distinctive features of innovation activities undertaken in the small and medium-sized industrial enterprises in Bulgaria

- Proposed are ideas for improving SMEs innovative activities.

\section{References}

Executive Agency for Promotion of Small and Medium-Sized Enterprises, (2016). A study into the entrepreneurship and prospects for innovation development in SMEs (2012-2013)

Evangelista R. (2000). Sectoral Patterns of Technological Change in Services. In: Economics of Innovation and New Technology, Vol. 9, 183-221

Iliev Y. (2005). Competitiveness of the Bulgarian industrial enterprises

Lawless and Fisher. (1990). Sources of Durable Competitive Advantage in New Products

Minarelli F., Raggi M., Viaggi D. (2014). Innovation in European food SMEs: determinants and links between types 
National statistical institute. (2017). 2014-2016-Innovation activity of the enterprises during the period

National statistical institute.(2017). Statistical reference book

Peteraf M. (2016). Dynamic Capabilities and Organizational Agility: Risk, Uncertainty and Entrepreneurial Management in the Innovation Economy,

Ren D., Zhang X, Yi J. (2010). Empirical Analysis on SME's Innovative Efficiency - A Case of SMEs in Guangdong Cluster of Materials Industry

Velev M. (2004). Analysis and evaluation of company competitiveness 